\title{
Spectroelectrochemical analysis of ion-transfer and adsorption of PAMAM dendrimer at a polarized liquid|liquid interface
}

\author{
Hirohisa Nagatani $^{\mathrm{a} * 1}$, Takeshi Ueno ${ }^{\mathrm{b}}$, and Takamasa Sagara ${ }^{\mathrm{a}}$ \\ a Department of Applied Chemistry, Faculty of Engineering, Nagasaki University, \\ Bunkyo 1-14, Nagasaki 852-8521, Japan \\ ${ }^{\mathrm{b}}$ Department of Materials Engineering and Molecular Science, Graduate School of \\ Science and Technology, Nagasaki University, Bunkyo 1-14, Nagasaki 852-8521, Japan
}

* Corresponding author. Tel./fax.: +81 958192675 ;

E-mail address: nagatani@nagasaki-u.ac.jp (H. Nagatani)

${ }^{1}$ ISE member 


\begin{abstract}
Interfacial behavior of the fourth generation polyamidoamine (G4 PAMAM) dendrimer at the water|1,2-dichloroethane (DCE) interface was studied by the cyclic voltammetry and the potential modulated fluorescence (PMF) spectroscopy. The irregular voltammetric responses were observed at positively polarized interfaces. Cyclic voltammogram was strongly dependent on $\mathrm{pH}$ and concentrations of G4 PAMAM dendrimer and organic supporting electrolyte. PMF spectroscopy was successfully used for analyzing the interfacial mechanism of the dendrimer by adding an anionic porphyrin derivative as a fluorescent probe. Results of the PMF measurements demonstrated that G4 PAMAM dendrimer was transferred across the interface accompanied by its adsorption step at $\mathrm{pH} 7$, while, in the alkaline condition, the adsorption process was not apparently involved in the interfacial behavior.
\end{abstract}

Keywords: PAMAM dendrimer; Liquid|liquid interface; Adsorption; Ion transfer; Potential modulated fluorescence 


\section{Introduction}

Dendrimers are among unique and nontraditional polymers with a well-defined macromolecular architecture consisting of a core, iterative branch units, and terminal groups [1]. The dendrimers are demonstrated to be capable of encapsulating various organic molecules, and the application of dendrimers to drug delivery systems has been studied extensively $[2,3]$. A full generation polyamidoamine (PAMAM) dendrimer is constructed based on an ethylenediamine core and terminated with amino groups. The fourth or higher generation PAMAM dendrimers are approximately taken as spherical molecules. The periphery region secludes the organic species captured in the interior from the solution phase and the higher generation PAMAM dendrimers are very useful for a molecular capsule (or container). The net charge on a dendrimer molecule is determined by the protonation of terminal amino groups and tertiary amines of the branch unit, and the intramolecular charge repulsion induces the conformation change $[4,5]$. The electrode potentials also contribute to the conformation change of dendrimer molecules adsorbed on an electrode surface [6, 7]. Recently, Arrigan and co-workers reported the fundamental electrochemical behavior of poly(propylenimine) and PAMAM dendrimers at the liquid|liquid interface [8]. The voltammetric responses indicated complex irreversible behavior for the third generation PAMAM dendrimer.

The liquid|liquid interface is specific two-dimensional reaction field used in separation sciences, nanomaterials formation and self-assembling of supramolecules [9]. The ion-partitioning and distribution properties of organic species have also been examined at the interface as a model of biomembrane systems by means of ion-transfer voltammetry. The transfer of ionic species across the interface often involves the 
adsorption process [10-12] and following ion-association of adsorbed monomer species $[13,14]$. The elucidation of the potential dependent adsorption behavior would be a key point to understand the ion-transfer mechanism.

In this work, the interfacial behavior of the fourth generation (G4) PAMAM dendrimer was investigated at the water|1,2-dichloroethane (DCE) interface under the potentiostatic control. G4 PAMAM dendrimer exhibited the irregular voltammetric responses at positively polarized interfaces. The potential modulated fluorescence (PMF) spectroscopy was employed in order to reveal the interfacial transfer mechanism of the dendrimer in detail. The PMF results demonstrated the $\mathrm{pH}$ dependence of the interfacial behavior of the positively charged dendrimer molecule.

\section{Experimental}

G4 PAMAM dendrimer schematically shown in Fig. 1 was purchased from Aldrich (10 $\mathrm{wt} \%$ in methanol) and prepared as an aqueous solution after removing methanol by drying in argon gas. The composition of the electrochemical cell was represented in Cell I.

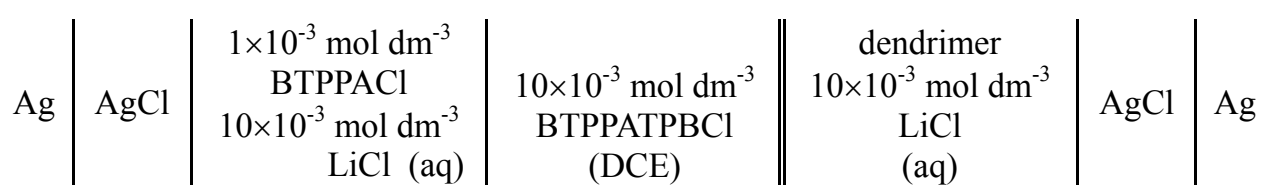

\section{Cell I}

The supporting electrolytes were $1.0 \times 10^{-2} \mathrm{~mol} \mathrm{dm}^{-3}$ lithium chloride for the aqueous phase and $1.0 \times 10^{-2}$ mol $\mathrm{dm}^{-3}$ bis(triphenylphosphoranylidene)ammonium terakis(4-chlorophenyl)borate (BTPPATPBCl) for the organic phases, respectively. 
BTPPATPBCl

was

prepared

by

metathesis

of

bis(triphenylphosphoranylidene)ammonium chloride (BTPPACl) (Fluka >98\%) and potassium tetrakis(chlorophenyl)borate (Aldrich 98\%). The organic solvent, 1,2-dichloroethane (DCE), was of HPLC grade (Wako Chemicals 99.7\%). 5,10,15,20-tetrakis(4-carboxyphenyl)porphyrinato zinc(II) tetrasodium salt (Na $\mathrm{ZnTPPC}_{4}$ was purchased from Frontier Scientific/Porphyrin Products. All other reagents were of the highest grade available and used without further purification. The aqueous solutions were prepared with purified water from a Milli-Q PLUS (Millipore). $\mathrm{A} \mathrm{pH}$ of the aqueous phase was controlled by adding $0.10 \mathrm{~mol} \mathrm{dm}{ }^{-3} \mathrm{HCl}$ for $\mathrm{pH} 1,0.050$ mol dm ${ }^{-3} \mathrm{LiH}_{2} \mathrm{PO}_{4} / \mathrm{LiOH}$ for $\mathrm{pH} 7$, and $0.001 \mathrm{~mol} \mathrm{dm}^{-3} \mathrm{LiOH}$ for $\mathrm{pH} 11$, respectively.

The spectroelectrochemical cell used in all measurements was analogous to one reported previously [15]. The water|DCE interface with a geometrical area of 0.50 $\mathrm{cm}^{2}$ was polarized by a four-electrode potentiostat (Hokuto Denko HA1010mM1A). Platinum wires were used as counter electrodes in both aqueous and organic phases. The Luggin capillaries were provided for the reference electrodes $(\mathrm{Ag} / \mathrm{AgCl})$ in both phases. The Galvani potential difference $\left(\Delta_{\mathrm{o}}^{\mathrm{w}} \phi \equiv \phi^{\mathrm{w}}-\phi^{\mathrm{o}}\right)$ was estimated by taking the formal transfer potential of tetramethylammonium as $0.160 \quad \mathrm{~V}$ and tetrapropylammonium as $-0.093 \mathrm{~V}[16]$.

In potential modulated fluorescence (PMF) measurements, $\mathrm{Na}_{4} \mathrm{ZnTPPC}$ was added to the aqueous phase and used as a fluorescent probe for the dendrimer. The incidence of excitation beam from an organic phase to the liquid|liquid interface was performed by a cw laser diode of $25.2 \mathrm{~mW}$ at $410 \mathrm{~nm}$ (Neoark TC20-4030S-2F-4.5) in total-internal reflection (TIR) [17]. The angle of incidence to the liquid|liquid interface $(\psi)$ was set as ca. $75^{\circ}$. The fluorescence emitted from the interfacial region 
was collected perpendicularly to the interface by an optical fiber fitted to a photomultiplier tube through a monochromator (JASCO CT-10). The ac modulated fluorescence signal was analyzed by a digital lock-in amplifier (NF LI 5640). The frequency of the ac potential modulation and the potential sweep rate were $1 \mathrm{~Hz}$ and 5 $\mathrm{mV} \mathrm{s}^{-1}$, respectively.

\section{Results and Discussion}

\subsection{Ion-transfer voltammetry at various $p H s$}

Cyclic votammograms (CVs) for G4 PAMAM dendrimer were significantly dependent on $\mathrm{pH}$ conditions of the aqueous phase. In an acidic condition, the anodic responses were increased gradually at potentials more positive than $0.1 \mathrm{~V}$ (Fig. 2a). The p $K_{\mathrm{a}}$ of G4 PAMAM dendrimer was reported as $9.20\left(\mathrm{p} K_{\mathrm{a}, 2}\right)$ for 64-terminal amino groups in the periphery moiety and $6.65\left(\mathrm{p} K_{\mathrm{a}, 1}\right)$ for 62-tertiary amines as branch points [18]. At $\mathrm{pH}$ 0.9, thus, G4 PAMAM dendrimers exist as the cationic species in the aqueous phase because of the protonation of terminal amino groups and tertiary amines. The anodic peak observed around $0.3 \mathrm{~V}$ was tentatively assigned as being due to the ion-transfer of G4 PAMAM dendrimer from the aqueous to organic phases and the cathodic peak around $0.2 \mathrm{~V}$ as the back transfer from the organic to aqueous phases. At $\mathrm{pH} \mathrm{7.1,} \mathrm{a}$ complex anodic wave was observed around $0.4 \mathrm{~V}$ in the forward scan, in which a small peak was found prior to the main peak (dot mark in Fig. 2b). The cathodic wave also exhibited irregular shape, in which the main peak at ca. $0.3 \mathrm{~V}$ (dot mark in Fig. 2b) was accompanied by broad cathodic responses in less positive potential regions. In the alkaline condition at $\mathrm{pH} 10.7$, the voltammetric responses totally decreased and the anodic peak was not clearly observed in the potential window, although the cathodic 
peak for a back transfer of the dendrimer from the organic phase was found around 0.4 $\mathrm{V}$ (Fig. 2c). The $\mathrm{pH}$ dependent CVs demonstrate that the interfacial process is changed by the protonation of the dendrimer. The voltammetric response in Figs. 2a and $\mathbf{2 b}$ indicates the complicated interfacial mechanism consisting of ion-transfer, adsorption and/or interfacial complex formation between the dendrimer and the organic anions. The cathodic peak current in all $\mathrm{pH}$ conditions, however, was almost proportional to the square root of the potential sweep rate $\left(v^{1 / 2}\right)$ (see Fig. 2: inset), although the anodic peak at $\mathrm{pHs} 0.9$ and 10.7 buried in the gradual increase of the anodic current in the higher potential region could not be analyzed. The linear dependence of the cathodic peak current illustrates the diffusion controlled charge transfer process from the organic to the aqueous phase at three different pHs. The anodic peak at $\mathrm{pH} 7.1$ also indicates the diffusion controlled transfer process from the aqueous to the organic phases. G4 PAMAM dendrimer in the solution can be regarded as a spherical molecule with radii reported between $2.2 \mathrm{~nm}$ and $2.5 \mathrm{~nm}$ in various conditions [5]. Therefore, a typical value of the diffusion coefficient of the dendrimer in DCE can roughly be estimated as $1.2 \times 10^{-6} \mathrm{~cm}^{2} \mathrm{~s}^{-1}$ at $298 \mathrm{~K}$ using Stokes-Einstein relation. The dendrimer and the reticulated polyelectrolyte can be considered as a multi-charged ion rather than an ensemble of singly charged segments [8, 19]. Net charges of transferred ions $(z)$ were estimated from the dependence of peak currents on $v^{1 / 2}$ by a tentative use of the Randles-Sevcik equation as 89 at $\mathrm{pH} 0.9,53$ at $\mathrm{pH} 7.1$ and 20 at $\mathrm{pH}$ 10.7, respectively. These $z$ values through the classical diffusion limited expression are roughly consistent with the protonation feature of the dendrimer, in which 64-terminal amino groups $\left(\mathrm{p} K_{\mathrm{a}, 2}=9.20\right)$ are fully protonated in neutral and acidic conditions and further protonation for tertiary amines $\left(\mathrm{p} K_{\mathrm{a}, 1}=6.65\right)$ takes place in more 
acidic condition ( $\mathrm{pH} 0.9$ ). On the other hand, $z$ decreases at higher $\mathrm{pHs}$. The $z=+20$ at $\mathrm{pH} 10.7$ is greater than the calculated value $(+2)$ based on $\mathrm{p} K_{\mathrm{a}, 2}$. The evaluation of the charge number on a transferred ion was further attempted for the anodic response by means of potential-step chronoamperometry. The current-time curves (not shown), unfortunately, could not be analyzed properly, because an additional charge transfer process took place simultaneously at a positive edge of the potential window as discussed below. Taken together, the $z$ value estimated from CVs should be taken as a phenomenological relative value.

In the acidic condition at $\mathrm{pH} 1, \mathrm{CVs}$ were strongly affected by concentrations of the dendrimer and the organic supporting electrolyte. The current response apparently exhibited the nonlinear relationship to the concentration of the dendrimer (Fig. 3a). In particular, the cathodic peak current in the presence of $70 \times 10^{-6} \mathrm{~mol} \mathrm{dm}^{-3}$ dendrimer exhibited weak dependence on $v$ (not proportional to $v^{1 / 2}$ ), indicative of the non diffusion-limited process at a higher concentration of the dendrimer. On the other hand, Fig. 3b shows that the voltammetric responses at potentials more positive than 0.4 $\mathrm{V}$ decreased with lowering the concentration of organic electrolyte (BTPPATPBCl). These results indicate that a gradual increase of anodic current at more positive potentials than the transfer potential of dendrimer could be due to the transfer of a hydrophobic anion, tetrakis(4-chlorophenyl)borate $\left(\mathrm{TPBCl}^{-}\right)$, from the organic to the aqueous phases, rather than the transfer and/or adsorption of the dendrimer. In the absence of the dendrimer, hydrophobic $\mathrm{TPBCl}^{-}$ions can not be transferred into the aqueous phase within the potential window (see Fig. 2: dotted line). Therefore, the interactions between $\mathrm{TPBCl}^{-}$and the dendrimer in the interfacial region such as ion-associations and complex formations are essential to a $\mathrm{TPBCl}^{-}$transfer at less 
positive potentials.

\subsection{Spectroelectrochemical analysis}

The PMF spectroscopy was employed in order to focus on the interfacial mechanism of G4 PAMAM dendrimer separately from other charge transfer processes related to the organic electrolyte. In this technique, an ac potential modulation is superimposed on the controlled dc bias. In the case that a potential-dependent process of the fluorescent ion takes place at the polarized liquid|liquid interface, the fluorescence intensity from the interfacial region is modulated with the same frequency as the potential modulation. By analyzing the phase shift (positive or negative) and its frequency response, the interfacial processes, especially adsorption process, can be studied with a high sensitivity and selectivity $[15,20]$.

G4 PAMAM dendrimer is not an efficient chromophoric species, and it is difficult to investigate the interfacial behavior of the dendrimer as itself through the absorption or fluorescence measurement. An anionic porphyrin derivative, ZnTPPC ${ }^{4-}$ added to the aqueous phase was used as a fluorescent probe for the dendrimer molecule with a molar ratio of $1: 1$ with respect to the dendrimer. Both UV-Vis absorption spectrum and emission spectrum exhibited considerable spectral changes, for instance, the absorption maximum wavelength at the Soret band of $\mathrm{ZnTPPC}^{4-}$ was red-shifted from $422.0 \mathrm{~nm}$ to $429.0 \mathrm{~nm}$ in the presence of the dendrimer at $\mathrm{pH} 7.2$ (Fig. 4a). The spectral changes confirm the effective binding of the anionic porphyrin to the cationic dendrimer in the aqueous phase. When adding $\mathrm{ZnTPPC}^{4-}$ more than 8 times greater molar ratio to the dendrimer, a dark solid, which is formed by the ion-association between G4 PAMAM dendrimer and $\mathrm{ZnTPPC}^{4-}$, was spontaneously precipitated in the 
aqueous solution, and the absorption spectrum indicated the presence of excess of free $\mathrm{ZnTPPC}^{4-}$ molecules. In the case that the fluorescent species is encapsulated in the interior of dendrimers, the fluorescence quenching of dye species takes place effectively $[21,22]$. The emission intensity observed in the present condition (molar ratio $=1: 1$ ) is, however, rather intense (Fig. 4b), indicating that porphyrin molecules bind to protonated amino groups close to the periphery moiety. The voltammetric features of G4 PAMAM dendrimer, such as anodic/cathodic peak potentials and phenomenological net charges estimated from CVs, were hardly influenced by the presence of equimolar of $\mathrm{ZnTPPC}^{4-}$ within the experimental errors (Fig. 5: inset). Only a slight peak shift was observed. The binding of $\mathrm{ZnTPPC}^{4-}$ to G4 PAMAM dendrimer would not seriously affect the interfacial mechanism of the dendrimer. The dependence of PMF responses on the Galvani potential difference is displayed in Fig. 5. As reported previously, ZnTPPC ${ }^{4-}$ exhibits the ion-transfer at ca. $-0.25 \mathrm{~V}$ and adsorption at negatively polarized water|DCE interfaces [13]. The absence of both PMF and voltammetric responses in the corresponding potential region demonstrates that ZnTPPC ${ }^{4-}$, which properly acts as a fluorescence probe, stably binds to G4 PAMAM dendrimer even at the polarized liquid|liquid interface. At $\mathrm{pH} 7.1$, the real $\left(\Delta F_{\mathrm{t}, \mathrm{re}}\right)$ and imaginary components $\left(\Delta F_{\mathrm{t}, \mathrm{im}}\right)$ of PMF responses around $0.44 \mathrm{~V}$ were obtained as positive and negative peaks (Fig. 5a). The real and imaginary components of the PMF response for an ion-transfer in TIR condition are described as Eqs. (1) and (2) [11, 20],

$$
\Delta F_{\mathrm{t}, \mathrm{re}}=\frac{4.606 \varepsilon \Phi I_{\mathrm{exc}}}{z F \cos \psi}\left[\frac{\Delta_{\mathrm{o}}^{\mathrm{w}} \phi_{\mathrm{1}} \sigma \omega^{-3 / 2}}{\left(R_{\mathrm{ct}}+\sigma \omega^{-1 / 2}\right)^{2}+\left(\sigma \omega^{-1 / 2}\right)^{2}}\right]
$$




$$
\Delta F_{\mathrm{t}, \mathrm{im}}=-\frac{4.606 \varepsilon \Phi I_{\mathrm{exc}}}{z F \cos \psi}\left[\frac{\Delta_{\mathrm{o}}^{\mathrm{w}} \phi_{1}\left(R_{\mathrm{ct}}+\sigma \omega^{-1 / 2}\right) \omega^{-1}}{\left(R_{\mathrm{ct}}+\sigma \omega^{-1 / 2}\right)^{2}+\left(\sigma \omega^{-1 / 2}\right)^{2}}\right]
$$

where $\Phi$ is the fluorescence quantum yield, and $I_{\text {exc }}$ is the excitation photon flux. $R_{\mathrm{ct}}, \sigma$, $\Delta_{\mathrm{o}}^{\mathrm{w}} \phi_{1}$ and $\omega$ are the charge transfer resistance, the Warburg term, the amplitude and the angular frequency of ac potential modulation, respectively. It has been established that the real and imaginary components of the PMF signals for an ion-transfer of a cationic species across the interface are expressed as positive and negative values at an ion-transfer potential, respectively [11]. On the other hand, the negative real and positive imaginary components are observed for an anionic species. In the present system, the PMF responses around $0.44 \mathrm{~V}$ in Fig. 5a were assigned to the ion-transfer of the positively charged dendrimer. At potential region between 0.35 and $0.50 \mathrm{~V}$, a further broad response with an opposite sign was superimposed on the ion-transfer peak around $0.44 \mathrm{~V}$. As a result, the broad response apparently splits to two peaks at $0.40 \mathrm{~V}$ and $0.48 \mathrm{~V}$. For an adsorption process, the peak width of the potential dependent PMF response is broaden, since a portion of the applied potential is only employed for the adsorption process from a bulk phase to the interface $[11,17,20]$. The real $\left(\Delta F_{\mathrm{a}, \mathrm{re}}^{\mathrm{o}}\right)$ and imaginary components $\left(\Delta F_{\mathrm{a}, \mathrm{im}}^{\mathrm{o}}\right)$ of the PMF response for an adsorption at an organic side of the interface are expressed as negative and positive values, respectively, by the surface coverage $\left(\theta_{0}\right)$, the adsorption $\left(k_{\mathrm{a}, 0}\right)$ and desorption rate constants $\left(k_{\mathrm{d}, 0}\right)[20]$,

$$
\begin{aligned}
& \Delta F_{\mathrm{a}, \mathrm{re}}^{\mathrm{o}}=-\frac{2.303 \varepsilon \Phi I_{\mathrm{exc}} \Gamma_{\mathrm{s}} S b z F}{R T}\left[\frac{\Delta_{\mathrm{o}}^{\mathrm{w}} \phi_{1}\left(k_{\mathrm{a}, 0} \alpha c_{0}\left(1-\theta_{0}\right)-k_{\mathrm{d}, 0}(\alpha-1) \theta_{0}\right)\left(k_{\mathrm{a}, 0} c_{0}+k_{\mathrm{d}, 0}\right)}{\left(k_{\mathrm{a}, 0} c_{0}+k_{\mathrm{d}, 0}\right)^{2}+\omega^{2}}\right] \\
& \Delta F_{\mathrm{a}, \mathrm{im}}^{\mathrm{o}}=\frac{2.303 \varepsilon \Phi I_{\mathrm{exc}} \Gamma_{\mathrm{s}} S b z F}{R T}\left[\frac{\Delta_{\mathrm{o}}^{\mathrm{w}} \phi_{1}\left(k_{\mathrm{a}, 0} \alpha c_{0}\left(1-\theta_{0}\right)-k_{\mathrm{d}, 0}(\alpha-1) \theta_{0}\right) \omega}{\left(k_{\mathrm{a}, 0} c_{0}+k_{\mathrm{d}, 0}\right)^{2}+\omega^{2}}\right]
\end{aligned}
$$


where $\Gamma_{\mathrm{s}}$ is the saturated surface concentration, $S$ is the illuminated surface area, $b$ is the portion of applied potential employed for adsorption process $(\sim 0.5), \alpha$ is overall transfer coefficient for adsorption process, $c_{0}$ is the bulk concentration. The broad PMF responses between 0.35 and $0.50 \mathrm{~V}$ with an opposite sign to the ion-transfer responses could be due to the adsorption process of the cationic dendrimer in the organic side of the interface. As is clear from in Figs. $\mathbf{2 c}$ and $\mathbf{5 b}$, the ion-transfer response of dendrimer is significantly decreased in alkaline condition ( $\mathrm{pH} 11.0)$, since the protonation of dendrimer hardly takes place. A slight negative shift of the transfer response was also observed in PMF, indicating less hydrophilicity of the dendrimer with a relatively smaller positive net charge. Furthermore, the PMF response associated with the adsorption process of the cationic species in the organic side of the interface was not clearly observed around the potential of the ion-transfer response (ca. $0.40 \mathrm{~V}$ ) at $\mathrm{pH}$ 11.0. It should, however, be noted that the PMF signals at more positive potential than $0.45 \mathrm{~V}$ were opposite in sign to the ion-transfer responses. A weak adsorption likely takes place at the organic side of the interface even in the alkaline condition.

The PMF results demonstrated significant differences of the interfacial mechanism depending on pHs. Schematic drawing of the transfer and adsorption mechanism of G4 PAMAM dendrimer is shown in Fig. 6. At $\mathrm{pH}$ 7, the positively charged dendrimer is transferred across the interface at ca. $0.4 \mathrm{~V}$ and the adsorption process takes place in the organic side of the interface with an increase in the bulk organic concentration of the dendrimer. In the alkaline condition, the ion-transfer process is the dominant interfacial process. 


\section{Conclusions}

The voltammetric behavior of G4 PAMAM dendrimer at the water|DCE interface was strongly influenced by the $\mathrm{pH}$ condition and the concentrations both dendrimer and organic electrolyte. The PMF spectroscopy was used for analyzing the interfacial mechanism of G4 PAMAM dendrimer by adding an anionic fluorescent probe, $\mathrm{ZnTPPC}^{4-}$. The PMF responses demonstrated that the dendrimer at $\mathrm{pH} 7$ is transferred across the interface accompanied by the adsorption step at the organic side of the interface. In the alkaline condition, the adsorption process is not apparently involved in the interfacial mechanism.

\section{Acknowledgements}

H. N. acknowledges to financial supports from Iketani Science and Technology Foundation (No.0191038-A) and Izumi Science and Technology Foundation (H19-J-90). This work was also partially supported by a Grant-in-Aid for Young Scientists (B) (No. 17750070) from the Ministry of Education, Culture, Sports, Science and Technology of Japan (MEXT). The authors are also indebted to Dr. Toshiyuki Osakai of Kobe University for valuable discussions.

\section{References}

[1] D.A. Tomalia, Prog. Polym. Sci. 30 (2005) 294-324.

[2] F. Aulenta, W. Hayes, S. Rannard, Eur. Polym. J. 39 (2003) 1741-1771.

[3] S. Svenson, D.A. Tomalia, Adv. Drug Deliv. Rev. 57 (2005) 2106-2129.

[4] W. Chen, D.A. Tomalia, J.L. Thomas, Macromolecules 33 (2000) 9169-9172.

[5] P.K. Maiti, T. Cagin, S.T. Lin, W.A. Goddard III, Macromolecules 38 (2005) 
979-991.

[6] T. Sagara, K. Nagata, H. Tsuruta, N. Nakashima, Chem. Commun. (2002) 2116-2117.

[7] R. Pericet-Camara, B.P. Cahill, G. Papastavrou, M. Borkovec, Chem. Commun. (2007) 266-268

[8] A. Berduque, M.D. Scanlon, C.J. Collins, D.W.M. Arrigan, Langmuir 23 (2007) $7356-7364$

[9] H. Watarai, N. Teramae, S. Sawada, (eds.), Interfacial Nanochemistry, Kluwer Academic/Plenum Publishers, New York, 2005.

[10] T. Kakiuchi, J. Electroanal. Chem. 496 (2001) 137-142.

[11] H. Nagatani, R.A. Iglesias, D.J. Fermín, P.-F. Brevet, H.H. Girault, J. Phys. Chem. B 104 (2000) 6869-6876.

[12] T. Osakai, H. Yamada, H. Nagatani, T. Sagara, J. Phys. Chem. C 111 (2007) 9480-9487.

[13] H. Nagatani, Z. Samec, P.-F. Brevet, D.J. Fermín, H.H. Girault, J. Phys. Chem. B 107 (2003) 786-790.

[14] H. Nagatani, S. Suzuki, D.J. Fermín, H.H. Girault, K. Nakatani, Anal. Bioanal. Chem. 386 (2006) 633-638.

[15] H. Nagatani, T. Sagara, Anal. Sci. 23 (2007) 1041-1048.

[16] H.H. Girault, D.J. Schiffrin, in A. J. Bard (ed.) Electroanalytical Chemistry, Vol. 15, Marcel Dekker, Inc., New York, 1989, pp. 1-141.

[17] H. Nagatani, T. Ozeki, T. Osakai, J. Electroanal. Chem. 588 (2006) 99-105.

[18] D. Leisner, T. Imae, J. Phys. Chem. B 107 (2003) 13158-13167.

[19] S. Ulmeanu, H.J. Lee, H.H. Girault, Electrochem. Commun. 3 (2001) 539-543. 
[20] H. Nagatani, D.J. Fermín, H.H. Girault, J. Phys. Chem. B 105 (2001) 9463-9473.

[21] P.M.R. Paulo, S.M.B. Costa, J. Phys. Chem. B 109 (2005) 13928-13940.

[22] M. Chai, A.K. Holley, M. Kruskamp, Chem. Commun. (2007) 168-170. 


\section{Captions}

Fig 1 Schematic drawing of molecular structure of G4 PAMAM dendrimer.

Fig. 2 Cyclic voltammograms measured in the presence of $1.0 \times 10^{-5} \mathrm{~mol} \mathrm{dm}^{-3} \mathrm{G} 4$ PAMAM dendrimer at (a) $\mathrm{pH} 0.9$, (b) 7.1, and (c) 10.7. The potential sweep rates were 10, 20, 50, 100, and $200 \mathrm{mV} \mathrm{s}^{-1}$. The dotted lines refer to CVs in the absence of G4 PAMAM dendrimer at $10 \mathrm{mV} \mathrm{s}^{-1}$. (inset) Sweep rate dependences of the peak current.

Fig. 3 Dependences of cyclic voltammogram at $\mathrm{pH} 1$ on the concentrations of (a) G4 PAMAM dendrimer and (b) BTPPATPBCl. The concentration of (a) BTPPATPBCl and (b) G4 PAMAM dendrimer were $10 \times 10^{-3} \mathrm{~mol} \mathrm{dm}^{-3}$ and $7.0 \times 10^{-6} \mathrm{~mol} \mathrm{dm}^{-3}$, respectively. The potential sweep rate was $50 \mathrm{mV} \mathrm{s}^{-1}$.

Fig. 4 (a) Typical absorption and (b) emission spectra of $\mathrm{ZnTPPC}^{4-}$ in the aqueous solution at $\mathrm{pH}$ 7.2. The solid and dashed lines refer to the spectrum in the presence and absence of equimolar of G4 PAMAM dendrimer, respectively. The excitation wavelength for emission spectra was $410 \mathrm{~nm}$. The concentration of $\mathrm{ZnTPPC}^{4-}$ was $7 \times 10^{-6} \mathrm{~mol} \mathrm{dm}^{-3}$

Fig. 5 Typical PMF responses for G4 PAMAM dendrimer at (a) $\mathrm{pH} 7.1$ and (b) 11.0 in the presence of equimolar of $\mathrm{ZnTPPC}^{4-}$. The solid and dashed lines refer to the real and imaginary components, respectively. The amplitude of potential modulation was $10 \mathrm{mV}$ for $\mathrm{pH} 7.1$ and $20 \mathrm{mV}$ for $\mathrm{pH}$ 11.0, respectively. (a: inset) Cyclic 
voltammogram measured at $5 \mathrm{mV} \mathrm{s}^{-1}$. The concentration of G4 PAMAM dendrimer and $\mathrm{ZnTPPC}^{4-}$ in the aqueous phase was $1.0 \times 10^{-5} \mathrm{~mol} \mathrm{dm}^{-3}$.

Fig. 6 Schematic drawing of the interfacial mechanism of G4 PAMAM dendrimer at $\mathrm{pH}$ 7 as studied by PMF spectroscopy. 


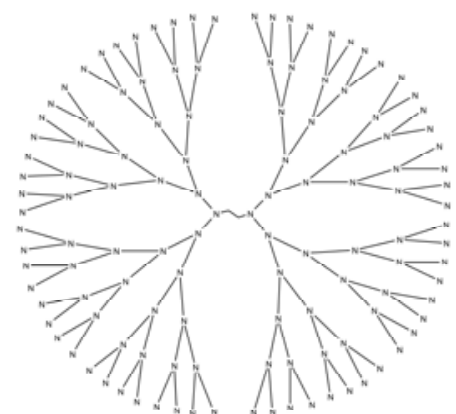

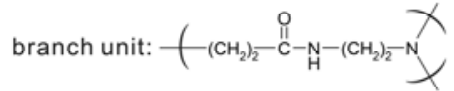

terminal unit: $-\left(\mathrm{CH}_{2}\right)_{2} \stackrel{\mathrm{C}}{\mathrm{C}}-\mathrm{N}-\left(\mathrm{CH}_{2}\right)_{2}-\mathrm{NH}_{2}$

Fig 1 Nagatani et al. 

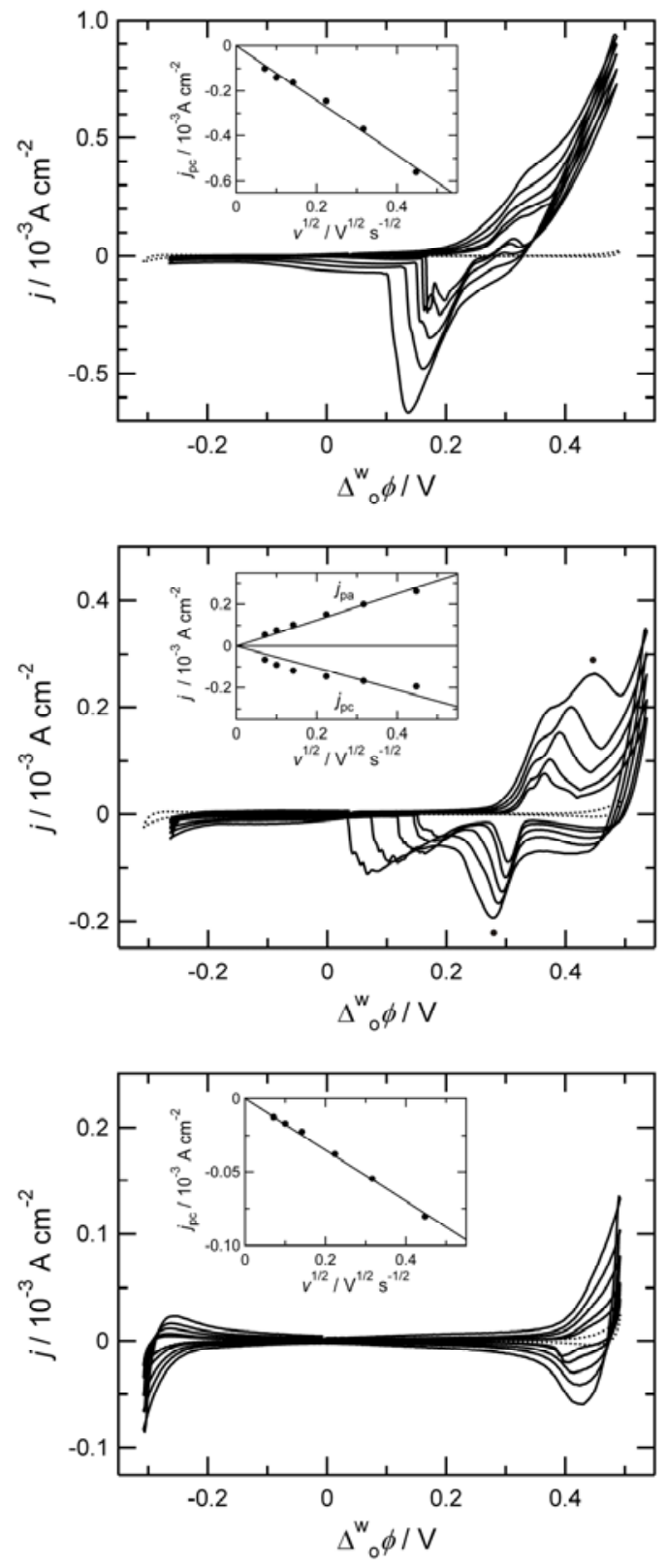

Fig. 2 Nagatani et al. 

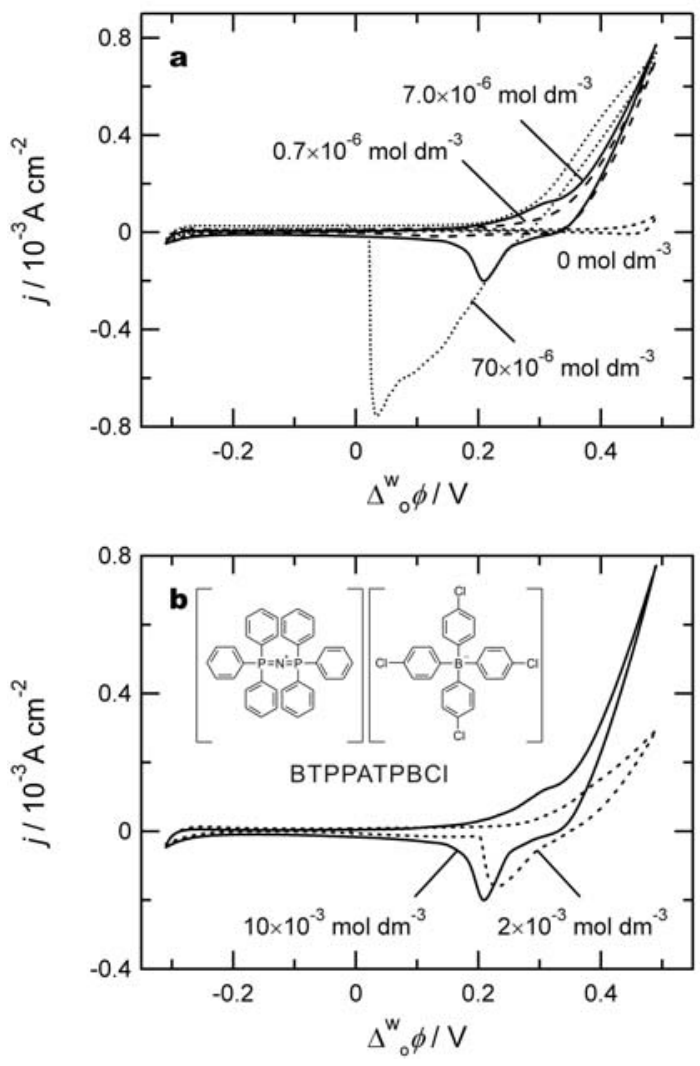

Fig. 3 Nagatani et al. 

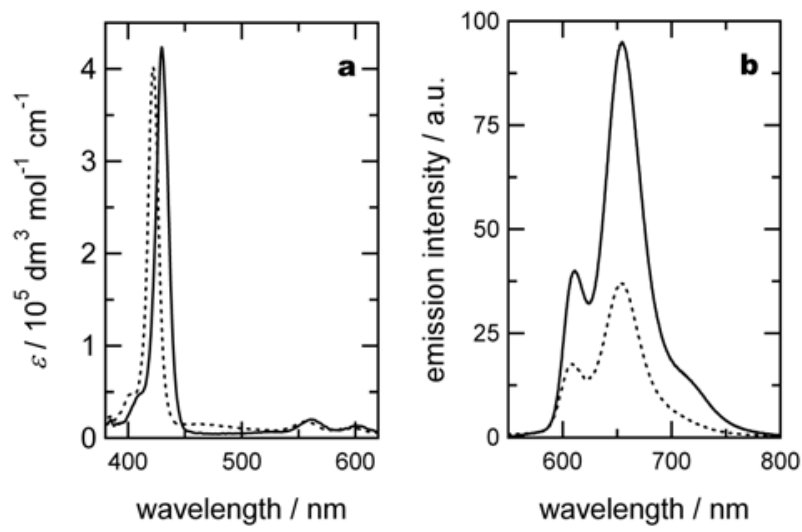

Fig. 4 Nagatani et al. 

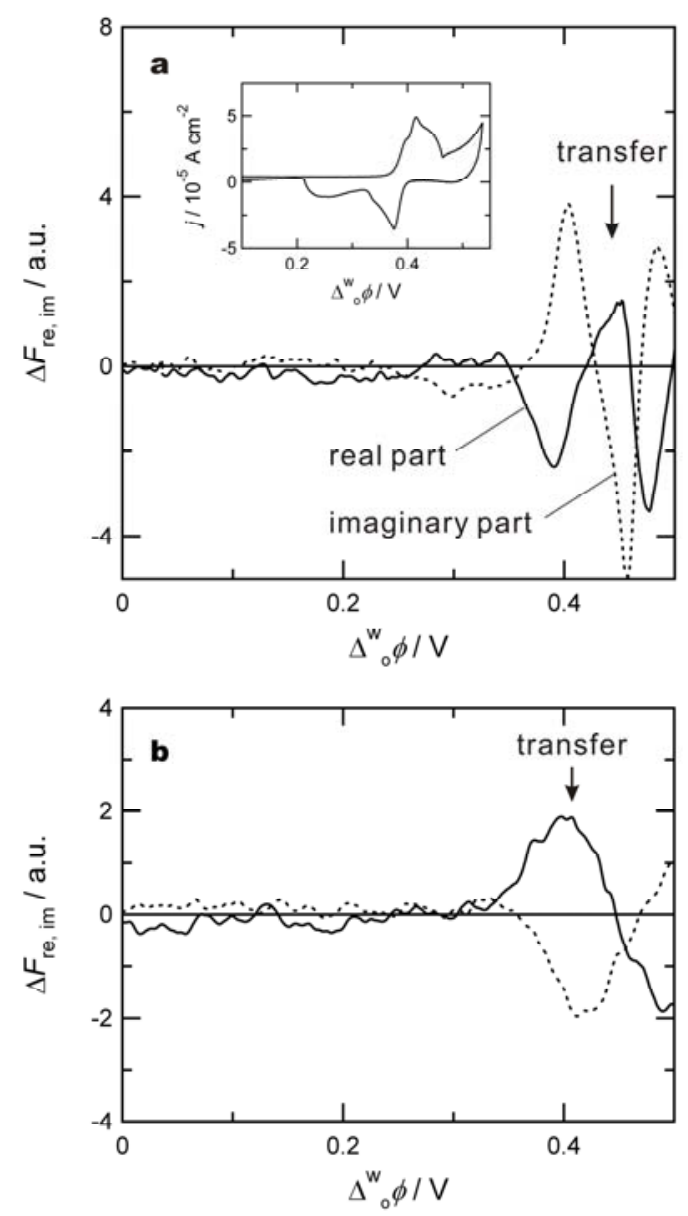

Fig. 5 Nagatani et al. 


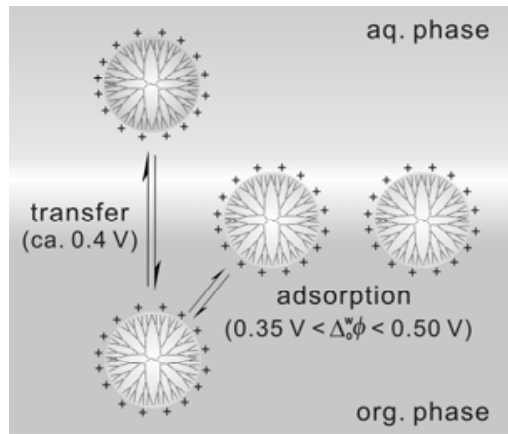

Fig. 6 Nagatani et al. 